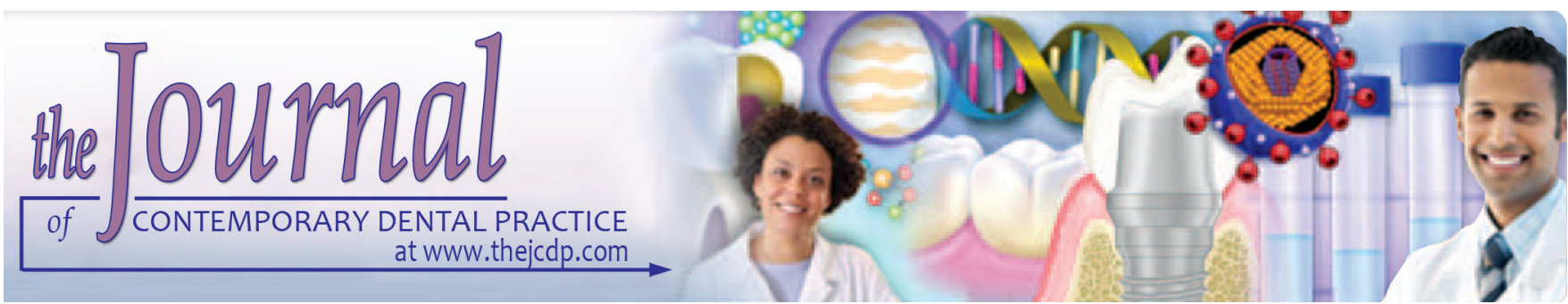

\title{
An In Vitro Comparative Evaluation of Shear Bond Strengths of Veneering Porcelain and Different Core Materials
}

\author{
${ }^{1}$ Rahul Nageshraj, ${ }^{2}$ Menon P Rajagopal, ${ }^{3}$ Sheejith Madapathy, ${ }^{4}$ Pradeep Samuel, ${ }^{5}$ Nidhin Ramabhadran, \\ ${ }^{6}$ Jyothis Mathew
}

\begin{abstract}
Aim: The aim of the present study was to evaluate and compare the bond strengths of different core structures to veneering porcelain.

Materials and methods: Sixty specimens were divided into 4 groups of 15 each. Specimen fabrication was done according to the International Organization for Standardization (ISO) specifications 9693:1999. Group 1 comprised core structure made of cast alloy, group 2 from sintered metal, group 3 from milled zirconia and group 4 milled zirconia without liner at the interface. The shear bond strengths were recorded and the values obtained were statistically examined.
\end{abstract}

Results: Highest values were recorded in group 3 and there were significant differences between groups 1 and 3 while groups 3 and 4 were not statistically different. This led us to imply that zirconia as a core structure provided maximum strengths and laser sintered metal came second. The results also pointed out that the role of the zirconia liner is not that crucial to attaining adequate strength.

Conclusion: The present study concluded that zirconia and laser sintered metal are excellent core materials and feasible alternatives to cast alloy. We also concluded from our study that a zirconia liner did not affect the bond strength significantly and is not absolutely essential.

Clinical significance: This study helps us to understand the role of materials used as core structures in enhancing the shear bond strength to veneer porcelains and also clarifies the role of a zirconia liner in the process.

Keywords: Laser sintered metal, Metal ceramic interface, Shear bond strengths, Veneering porcelain, Zirconia liner.

1,2,4-6 Department of Prosthodontics, Educare Institute of Dental Sciences, Malappuram, Kerala, India

${ }^{3}$ Department of Prosthodontics, KMCT Dental College, Calicut, Kerala, India

Corresponding Author: Rahul Nageshraj, Department of Prosthodontics, Educare Institute of Dental Sciences, Malappuram, Kerala, India, Phone : +917012927983, e-mail: rahulnageshraj@gmail.com
How to cite this article: Nageshraj R, Rajagopal MP, Madapathy S, Samuel P, Ramabhadran N, Mathew J. An In Vitro Comparative Evaluation of Shear Bond Strengths of Veneering Porcelain and Different Core Materials. J Contemp Dent Pract 2018;19(12):1437-1443.

Source of support: Nil

Conflict of interest: None

\section{INTRODUCTION}

Metal ceramics and all ceramics in different forms dominate the field of esthetic restorations and prosthesis currently. Historically, the lost wax process has been used to make metal ceramic frameworks but with advances in technology, core substructures for ceramic restorations are increasingly being made with direct metal laser sintering and crassulacean acid metabolism (CAM). The process is vastly simpler and less prone to errors by the technician. The only hindrance remains the cost of the procedure due to expensive armamentarium and that too is coming down rapidly as with any technological advance. The success of the ceramic prosthesis partly depends on the bonding between the esthetic veneering porcelain and the core structure. ${ }^{1}$

Bonding failures in porcelain fused to metal prosthesis have been reported at 2.3 to $8 \% .^{2-4}$ Chipping of veneering porcelain has been observed in posterior zirconia-based restorations at 6 to $25 \%$ within a 5 year period, ${ }^{5}$ improving the bond strength between the core structure and the veneering porcelain can reduce costly remakes and repairs.

A number of mechanical tests are available to evaluate the bond strength at the interface but the Schwickerath crack initiation test first proposed by Lenz et al. ${ }^{6}$ is a reliable gold standard and has been described in ISO specifications 9693:1999 to determine bond strengths. The bond strengths of porcelain to cast $\mathrm{Cr}-\mathrm{Co}$ alloy is reliable and well documented, but literature is sparse 
comparing the bond strengths of veneering porcelain to laser sintered $\mathrm{Cr}$-Co alloy and machined zirconia. The purpose of this in vitro study is to evaluate the bond strengths of veneering porcelain to laser sintered $\mathrm{Cr}-\mathrm{Co}$ alloy, zirconia and to compare it with the Cr Co alloy fabricated by the lost wax process.

\section{MATERIALS AND METHODS}

The present in-vitro study was carried out to compare the bond strength of porcelain to zirconia, cast Co-Cr alloy and direct metal laser sintered $\mathrm{Co}-\mathrm{Cr}$ core materials. The study comprised of 60 specimens and divided into 4groups, each group contained 15 specimens.

Different groups for bond strength testing were categorized as:

- Group 1 (G1): Co-Cr alloy specimens made from conventional lost wax casting method.

- Group 2 (G2): Co-Cr alloy specimens made from direct metal laser sintering technique.

- Group 3 (G3): Zirconia specimens made by CAD/ CAM milling

- Group 4 (G4): Zirconia specimens without liner

\section{SPECIMEN PREPARATION}

\section{Fabrication of Co-Cr Metal Specimen Using the Lost Wax Technique}

Acrylic resin blocks of $25 \mathrm{~mm} \times 3 \mathrm{~mm} \times 0.5 \mathrm{~mm}$ were fabricated according to standard ISO 9693:1999. Impressions of these acrylic blocks were made using putty consistency polyvinylsiloxane impression material. Molten casting wax was poured into these mold spaces and rectangular wax strips were obtained. These wax strips were sprued and invested with phosphate bonded investment material. The investments were heated in a burnout furnace to $900^{\circ} \mathrm{C}$ for 30 minutes to eliminate the wax. Then, the casting was done with a Co-Cr alloy in induction casting machine, the castings were removed and the specimens were trimmed, polished and air abraded with $150 \mu \mathrm{m}$ aluminum oxide.

\section{Fabrication of Co-Cr Metal Specimen Using Laser Sintering}

Selective laser melting technology (Fig. 1) is an additive manufacturing technology which creates 3-dimensional metal parts by using laser power to melt metal powders layer by layer according to computer-aided design data. Specimens of dimension $25 \mathrm{~mm} \times 3 \mathrm{~mm} \times 0.5 \mathrm{~mm}$ were designed (3 Shape Designing Software) in the computer. With the help of laser melting technology machine Co-Cr metal specimen were made (Fig. 2). The specimens were trimmed polished and air abraded with $150 \mu \mathrm{m}$ aluminum oxide.

\section{Fabrication of Zirconia Specimens Uusing CAD/CAM Milling}

Zirconia specimens of dimension $25 \mathrm{~mm} \times 3 \mathrm{~mm} \times 0.5 \mathrm{~mm}$ were designed with the help of 3 shape designing Software (Fig. 3) and milled to a specified dimension and then fully sintered using sintering machine (Fig. 4).

\section{Porcelain Application on Metal Specimens}

Each specimen was subjected to ultrasonic cleaning for 10 minutes and then air dried to ensure the removal of residual cleaner. Then each specimen was subjected to oxidation at $980^{\circ} \mathrm{C}$. A thin layer of wash opaque porcelain, a layer of opaque porcelain, and a layer of body porcelain (IPS classic) were fused to the central rectangular area $(3 \mathrm{~mm} \times 8 \mathrm{~mm})$ of the metal bar in succession to achieve a total thickness of $1.5 \mathrm{~mm}$ (in compliance with ISO Standard 9693). The firing was performed in a furnace simulating the standard level for clinical crown manufacture. All the specimens were glazed at $920^{\circ} \mathrm{C}$. Measurements in multiple locations were made using metal thickness measuring caliper to verify the symmetrical thickness of the porcelain.
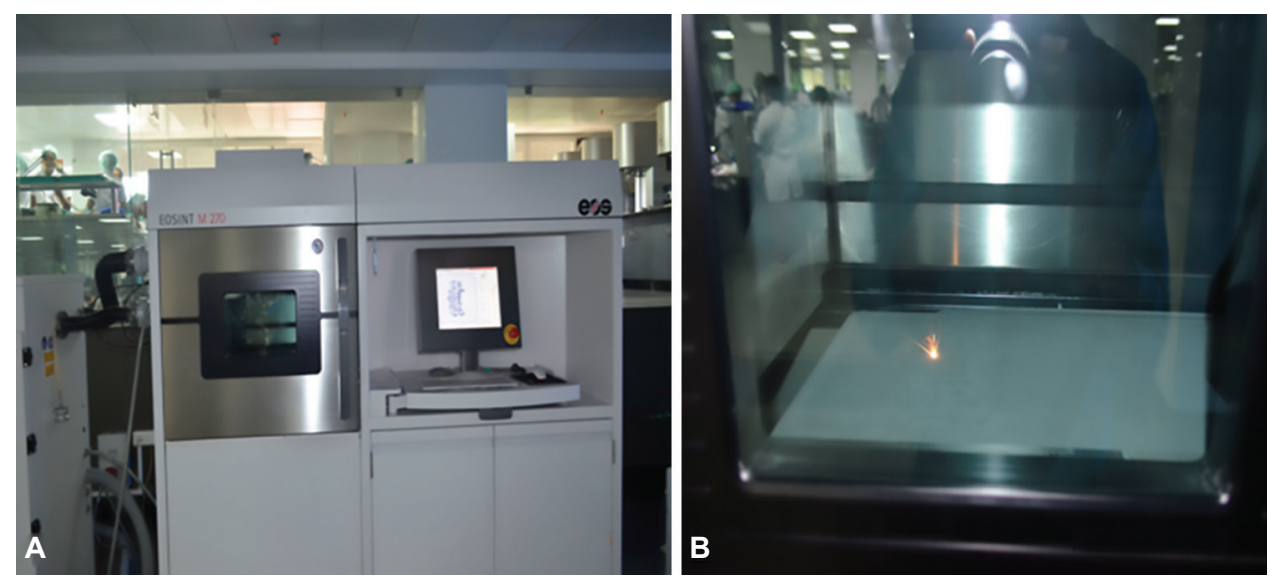

Figs 1A and B: (A) Selective laser melting (EOSINT M270 system); (B) Co-Cr alloy specimens fabricated by laser 


\section{Porcelain Application on Zirconia}

Before the porcelain application, each of the metal specimens was subjected to sandblasting with aluminum oxide of $110 \mu \mathrm{m}$. Then each specimen was subjected to ultrasonic cleaning for 10 minutes and then air dried to

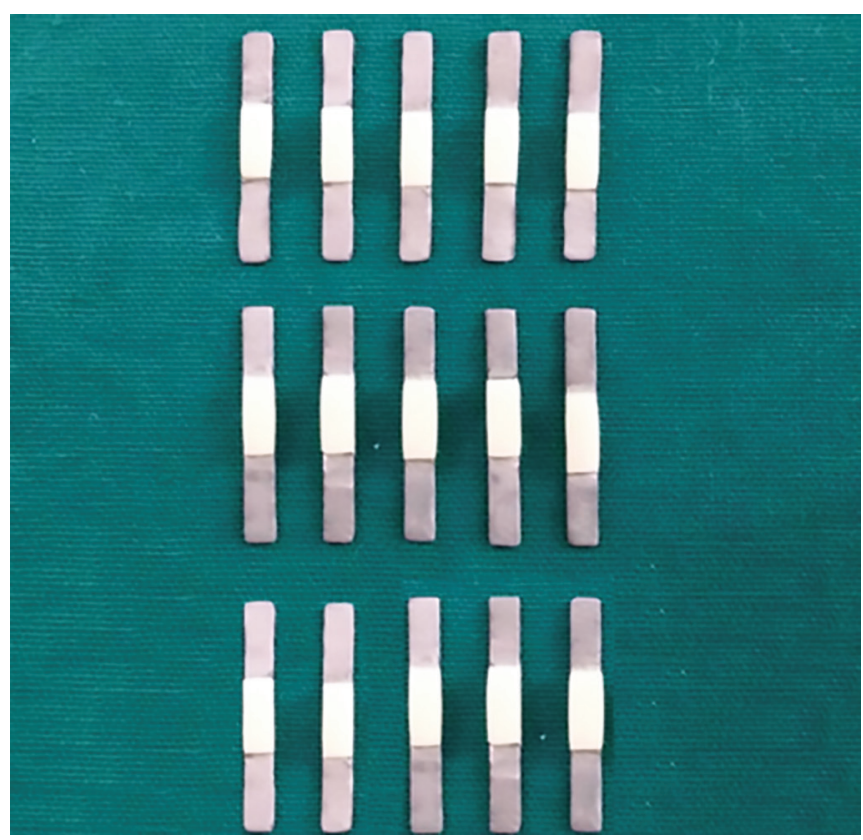

Fig. 2: Finished SLM Co-Cr specimens ensure the removal of residual cleaner. A thin layer of zirconia liner were fired followed by a layer of wash opaque porcelain, a layer of opaque porcelain, and a layer of body porcelain (IPS e.max ceram) were fused to the central rectangular area $(3 \mathrm{~mm} \times 8 \mathrm{~mm})$ of zirconia specimen in succession to achieve a total thickness of $1.5 \mathrm{~mm}$ (in compliance with ISO Standard 9693). The firing was performed in a furnace, simulating the standard level for clinical crown manufacture. All the specimens were glazed at $725^{\circ} \mathrm{C}$. The veneering ceramic was fired according to the respective manufacturer's recommendations.

\section{Bond Strength of Porcelain to Underlying Cores}

Each specimen was placed with its porcelain side facing downward. The two ends of each specimen were placed on the base of the universal testing machine (Fig. 5) with a hollow in the center with the diameter of $20 \mathrm{~mm}$. A crosshead with a diameter of $0.9 \mathrm{~mm}$ was loaded at the center of the specimen at a speed of $1.0 \mathrm{~mm} /$ minute until fracture occurred. The porcelain bond strength was calculated by using the formula $\mathrm{b}=\mathrm{k} \times \mathrm{F}_{\text {fail }}$; where $\mathrm{F}_{\text {fail }}$ represented the fracture force recorded in the test, and the coefficient $\mathrm{k}$ was a function of the thickness of the metal substrate $\left(\mathrm{d}_{\mathrm{M}}\right)$ and the Young's Modulus of the material $\left(\mathrm{E}_{\mathrm{M}}\right)$.
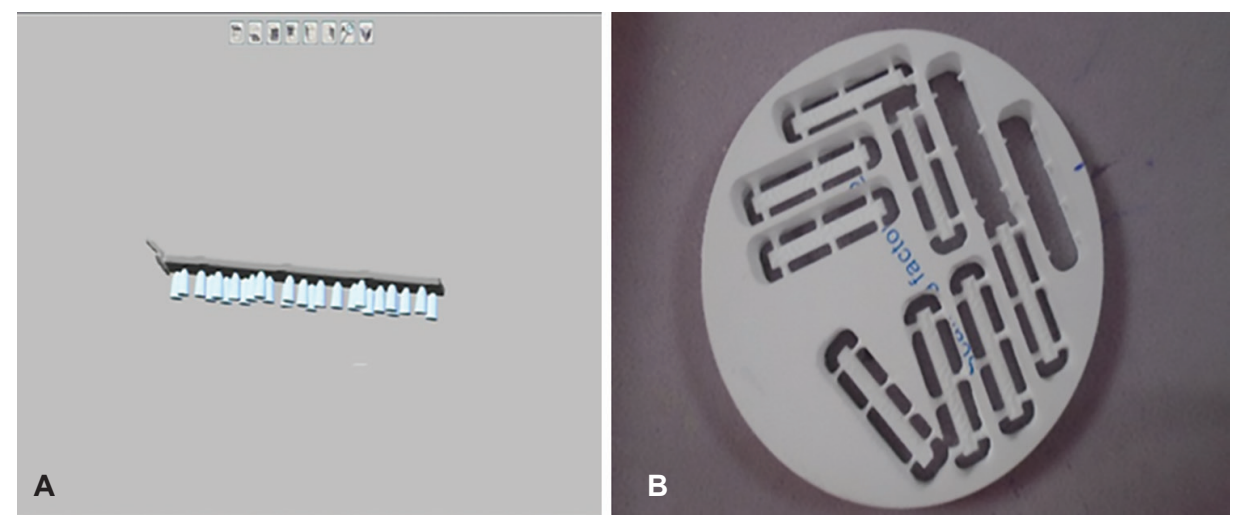

Figs 3A and B: (A) Specimens designed in CAD software (3 Shape designing software); (B) Milled zirconia specimens
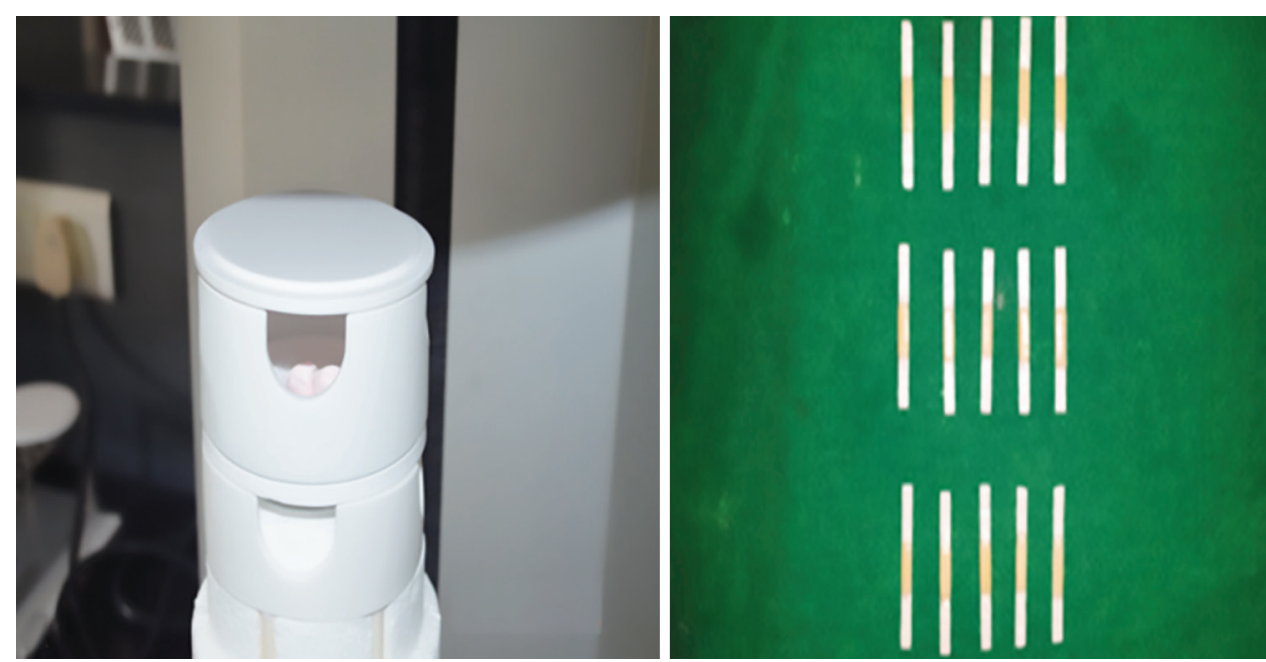

Figs 4A and B: (A) Sintering machine; (B) Finished zirconia specimens 


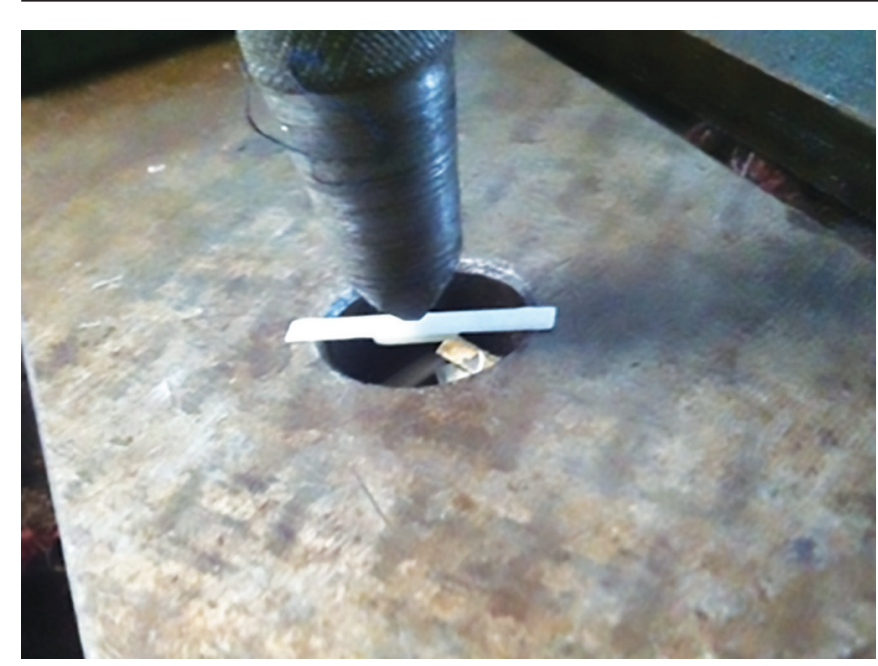

Fig. 5: Specimen in universal testing machine

\section{Statistical Analysis}

Results were analyzed using one-way analysis of variance (ANOVA) to identify a statistically significant difference in bond strength among the specimen groups.

\section{RESULTS}

The sixty specimens were tested in the universal testing machine. The fracture load $\left(\mathrm{F}_{\text {fail }}\right)$ of the specimen was measured by placing each specimen in a universal testing machine, at a crosshead speed of $1 \mathrm{~mm} / \mathrm{min}$ until the specimens fractured.

The individual $F_{\text {fail }}$ values of the specimen are as mentioned in Table 1.

The mean bond strength of the group1 to group 4 is as shown in Table 2 and Graph 1. Highest mean bond strength was recorded in Group 3 (85.84MPa) followed by group $4(80.41 \mathrm{MPa})$. The lowest mean bond strength was recorded in group $1(54.21 \mathrm{MPa})$. This table shows that the highest bond strength values were seen in the zirconia groups followed by laser sintered Co-Cr alloy and cast $\mathrm{Co}-\mathrm{Cr}$ alloy respectively.

Analysis of variance (ANOVA) was applied to determine the statistical implication of the results obtained (Table 3). The table value shows confidence interval of various groups and the p-values. It was evident that the differences between grades 1, 2 and 3 were statistically significant $(\mathrm{p}=0.000)$. However, the differences between the group 3 and group 4 were statistically insignificant.

\section{DISCUSSION}

The interface between the core substructure and veneering porcelain can be a source of concern in terms of debonding. Maximizing the bond strength at this interface is important to prevent unpleasant clinical situations. Whenever the core structure is base metal, the bond is primarily chemical and secondarily mechanical. ${ }^{7}$ The oxide layer at the interface is primarily responsible for the chemical bond whereas sandblasting and cleaning improve mechanical interlocking and wettability. ${ }^{8}$ Previous studies focusing on the metal-ceramic interface have found adequate strengths which ensure clinical longevity. ${ }^{9}$ Most of the research has dealt with the cast metal alloy, but studies on the laser sintered metal surface are relatively few. Wu et al. ${ }^{10}$ compared cast alloys to selective laser melted (SLM) alloys and found that the mechanical properties of SLM alloys were significantly greater but did not differ significantly in their bond strengths to porcelain. This finding was corroborated by Akova et al. ${ }^{11} \mathrm{~A}$ few authors have tested the bond strengths of titanium to porcelain as titanium is being used increasingly. ${ }^{12,13}$ The role of titanium as a core structure

Table1: Failure load $\left(\mathrm{F}_{\text {fai }} \mathrm{l}\right)$ of veneering porcelain to the underlying core materials

\begin{tabular}{rllll}
\hline & Group 1 & Group 2 & Group 3 & Group 4 \\
\cline { 2 - 5 } Specimen & Cast Co-Cr alloy (MPa) & Laser sintered Co-Cr alloy (MPa) & Zirconia (MPa) & Zirconia without liner (MPa) \\
\hline 1 & 16 & 18.66 & 23.33 & 22 \\
2 & 15.33 & 18 & 24 & 23 \\
3 & 12 & 17.33 & 21.33 & 21 \\
4 & 14 & 18.66 & 24 & 22 \\
5 & 16.66 & 18.66 & 23.33 & 21.33 \\
6 & 16 & 18 & 21.33 & 21.33 \\
7 & 15.33 & 18.66 & 24.66 & 23 \\
8 & 14.66 & 16 & 24 & 22 \\
9 & 17.33 & 17.22 & 23.33 & 23.33 \\
10 & 16 & 18.66 & 23.33 & 21.33 \\
11 & 15.33 & 19.33 & 25.33 & 20 \\
12 & 16 & 18.66 & 21.33 & 21 \\
13 & 14.66 & 18 & 22 & 23 \\
14 & 12.66 & 20 & 23.33 & 22 \\
15 & 14 & 18.66 & 23.33 & \\
\hline
\end{tabular}


is highly debatable and it is the opinion of the authors that using titanium as a core structure serves no specific advantages but at the same time, it has many disadvantages namely difficulty in casting, controlling oxide layer thickness and increased expense.

The bonding mechanisms of zirconia and veneer ceramic are poorly understood. ${ }^{5}$ Some authors have advised particle airborne abrasion and liner materials to improve bond strengths. ${ }^{14}$ There have been a lot of

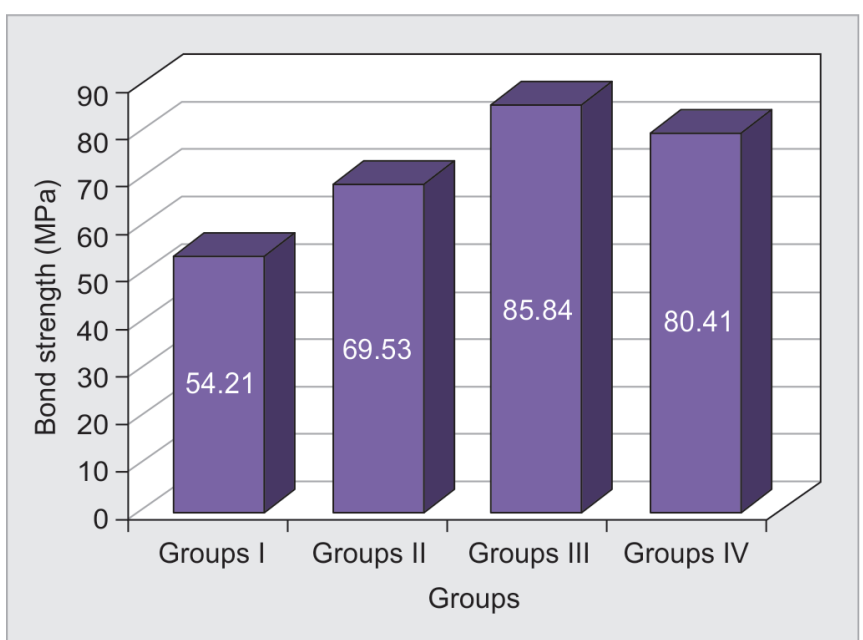

Graph 1: Mean bond strength values of four groups studies on deciding the optimum particle size and material for particle abrasion and taking many factors into account, the authors have decided to keep the size at 110 microns. The veneering ceramic used for zirconia specimens differ in the fact that their particle size is lesser and may provide better adaptation to the zirconia surface. It is common practice to place a zirconia liner on the cleaned and blasted surface. This liner contains a few oxides which are supposed to improve bonding. The chemical composition of the liner used in this study was silica dioxide $(\mathrm{SiO} 2$, $70.7 \%)$, aluminium oxide $\left(\mathrm{Al}_{2} \mathrm{O}_{3}, 11.5 \%\right)$, calcium oxide $(\mathrm{CaO}, 0.6 \%)$, magnesium oxide $(\mathrm{MgO}, 0.5 \%)$, sodium bicarbonate $\left(\mathrm{Na}_{2} \mathrm{CO}_{3}, 7.4 \%\right)$, lithium carbonate $\left(\mathrm{Li}_{2} \mathrm{CO}_{3}\right.$, $0.3 \%)$, and boron trioxide $\left(\mathrm{B}_{2} \mathrm{O}_{3}, 0.8 \%\right)$ as described by Kim et al. ${ }^{14}$ In that particular study, the results showed an increased possibility of interfacial failure with the application of a liner and suggested that air particle abrasion could be more effective. This study's results prove that the liner is not a significant factor in the bond strength as the differences in values of group 3 and 4 are not statistically significant even though the mean bond strengths of group 3 are better than 4 . Some studies have actually shown a reduction in bond strengths with the application of liner. ${ }^{15}$ The tensile bond strength

Table 2: Bond strength values of veneering porcelain to the underlying core materials

\begin{tabular}{cllll}
\hline & Group 1 & Group 2 & Group 3 & Group 4 \\
\hline Specimen & Cast Co-Cr alloy (MPa) & Laser sintered Co-Cr alloy (MPa) & Zirconia (MPa) & Zirconia without liner (MPa) \\
\hline 1 & 57.60 & 70.90 & 86.32 & 81.4 \\
2 & 55.18 & 68.40 & 88.88 & 85.1 \\
3 & 43.20 & 65.85 & 78.92 & 77.7 \\
4 & 50.40 & 70.90 & 88.88 & 81.4 \\
5 & 59.97 & 70.90 & 86.32 & 77.7 \\
6 & 57.60 & 68.40 & 78.92 & 77.7 \\
7 & 55.18 & 70.90 & 91.24 & 85.1 \\
8 & 52.77 & 60.80 & 88.88 & 81.4 \\
9 & 62.38 & 65.43 & 86.32 & 85.1 \\
10 & 57.60 & 70.90 & 86.32 & 81.4 \\
11 & 55.18 & 73.45 & 93.72 & 74 \\
12 & 52.60 & 70.90 & 78.92 & 74 \\
13 & 52.77 & 68.40 & 81.40 & 77.7 \\
14 & 45.36 & 76 & 86.32 & 85.1 \\
15 & 50.40 & 70.90 & 86.32 & 81.4 \\
Mean & 54.21 & 69.53 & 85.84 & 80.41 \\
\hline
\end{tabular}

Table 3: Difference in bond strength between the four groups using ANOVA test

\begin{tabular}{|c|c|c|c|c|c|c|c|}
\hline \multirow[b]{2}{*}{ Groups } & \multirow[b]{2}{*}{$N(\mathrm{MPa})$} & \multirow[b]{2}{*}{ Mean } & \multirow{2}{*}{$\begin{array}{l}\text { Standard } \\
\text { Deviation }\end{array}$} & \multicolumn{2}{|c|}{ Confidence Interval at $95 \%$} & \multirow[b]{2}{*}{$F$} & \multirow[b]{2}{*}{$p$} \\
\hline & & & & Lower & Upper & & \\
\hline G1 & 15 & 54.2127 & 5.21974 & 51.3221 & 57.1033 & 155.6556 & 0.000 \\
\hline G2 & 15 & 69.5353 & 3.59326 & 67.5455 & 71.5252 & & \\
\hline G3 & 15 & 85.8453 & 4.50186 & 83.3523 & 88.3384 & & \\
\hline G4 & 15 & 80.4121 & 3.8213 & 78.4794 & 82.3472 & & \\
\hline
\end{tabular}

$\mathrm{N}=$ Number of observations, $\mathrm{F}=$ Fischer's value, $\mathrm{p}=$ probability value 
values of this study $(85.84 \mathrm{MPa})$ in group 3 namely zirconia specimens show that surface treatment and liner application improves bond strengths. The results are statistically significant and hence the routine use of zirconia as a core material in the future can be a feasible alternative. Similar study designs metal and ceramic samples have been noted in the literature. Askanani et al. ${ }^{16}$ assessed the shear and flexural strength of zirconia and high noble alloys with their corresponding porcelains. They concluded that bond strengths of zirconia specimens were significantly higher than the metal groups regardless of thermal cycling. Choi et al. ${ }^{17}$ evaluated the shear bond strengths of zirconia and metal alloys with their corresponding porcelains using scanning electron micrographs and concluded that the zirconia specimens showed significantly higher bond strengths and that cohesive failure originated in the loaded side while adhesive failures occurred at the unloaded side.

The present study employed the three points bending test to measure the tensile bond strengths. All specimens tested showed bond strengths higher than $25 \mathrm{MPa}$ which is the minimum acceptable strength required by ISO 9693:1999. ${ }^{18}$ This led us to imply that metal laser sintering and CAD/CAM milled zirconia can be acceptable alternatives to traditional casting to provide predictable core substructures. Milling metal would be faster than sintering, but the tool wear associated with metal milling would increase the expense of the procedure. It is the opinion of the authors that with improvements in CAD, milling of metal could be the easier option in future. In this study, the group 2 specimens had significantly greater bond strengths than group 1 which is consistent with the findings of Xiang nan et al. ${ }^{9}$ They identified an intermediate layer between the laser sintered metal and porcelain which supposedly improved bond strengths. Studies have used X-ray spectroscopy and electron probe microanalyzer analyses (EPMA) to show an elemental interpenetration at this interface. This could explain the statistically significant differences between groups 1 and 2 . The mechanical properties of the laser sintered metal are superior as demonstrated by Wu et al. ${ }^{10}$

The fact that group 3 in this study showed the highest strength values implies a significant positive interaction between core zirconia and veneer porcelain. An analysis and visual observation of the fracture sites revealed that the metal specimens showed delamination from the interface but the zirconia specimens showed a cohesive fracture. This may be because the three point bending test employed led to bending of the metal specimens whereas zirconia being a brittle material would not bend and led to bulk fracture and that it may not actually be a true reflection of the interface bond strength. It is the opinion of the authors that further research should focus on this interface and attempt to elucidate the exact mechanism of bonding. The results of this study thus would suggest that laser sintered metal and zirconia are viable and promising alternatives to conventional lost wax processed metal alloys and thus can significantly reduce technical errors and intricacies. It has also been seen that the marginal adaptation and accuracy provided by sintering and milling are consistently superior to the lost wax technique. ${ }^{19-21}$

\section{CONCLUSION}

Chipping, delamination, and fracture of veneering porcelain can be frustrating to the clinician and the patient. Maximizing the bond strength at the interface can save a lot of time and expense. This study illustrates that zirconia and laser sintered metal are reliable alternatives to conventionally cast alloy as a core substructure and it also shows that a liner application on zirconia is an optional procedure.

\section{REFERENCES}

1. Son MK, Choe HC. Evaluation of interfacial bonding strength between laser textured metal coping and porcelain. Procedia Engineering 2011; 10:2286-2289.

2. Libby G, Arcuri MR, LaVelle WE, Hebl L. Longevity of fixed partial dentures. J Prosthet Dent. 1997;78:127-131.

3. Strub JR, Stiffler S, Scharer P. Causes of failure following oral rehabilitation: biological versus technical factors. Quintessence International 1988;19:215-222.

4. Kim B, Zhang Y, Pines M, Thompson VP. Fracture of porcelain-veneered structures in fatigue. Journal of Dental Research 2007;86:142-146.

5. Saito A, Komine F, Blatz MB, Matsumura H. A comparison of bond strength of layered veneering porcelains to zirconia and metal. J Prosthet Dent 2010;104:247-257.

6 Lenz J, Schwarz S, Schwickerath H, Sperner F, Schafer A. Bond strength of metal-ceramic systems in three-point flexure bond test. J Appl Biomater 1995;6:55-64.

7. Anusavice KJ. Phillips' science of dental materials. Philadelphia: Saunders; 2003.

8. Yao L, Peng C, Wu J. Wettability and bond strength between Lucite-reinforced dental porcelains and Co-Cr alloy. J Prosthet Dent 2013;110:515-520.

9. Xiang N, Xin XZ, Chen J, Wei B. Metal-ceramic bond strength of $\mathrm{Co}-\mathrm{Cr}$ alloy fabricated by selective laser melting. J Dent 2012;40(6):453-457.

10. Wu L, Zhu H, Gai X, Wang Y.Evaluation of the mechanical properties and porcelain bond strength of cobalt-chromium dental alloy fabricated by selective laser melting. J Prosthet Dent 2014;111(1):51-55.

11. Akova T, Ucar Y, Tukay A, Balkaya MC, Brantley WA. Comparison of the bond strength of laser-sintered and cast base metal dental alloys to porcelain. Dent Mater.2008;24(10):1400-1404. 
12. Reyes MJ, Oshida Y, Andres CJ, Barco T, Hovijitra S, Brown D. Titanium-porcelain system. Part III: effects of surface modification on bond strengths. Biomed Mater Eng 2001;11:117-136.

13. Zinelis S, Barmpagadaki X, Vergos V,Chakmakchi M, Eliades G. Bond strength and interfacial characterization of eight low fusing porcelains to cp Ti. Dent Mater 2010;26:264-273.

14. Kim HJ, Lim HP, Park YJ, Vang MS. Effect of zirconia surface treatments on the shear bond strength of veneering ceramic. J Prosthet Dent 2011;105:315-322.

15. Fischer J, Stawarczyk B, Sailer I, Hammerele CH. Shear bond strength between veneering ceramics and ceria-stabilized zirconia/alumina. J Prosthet Dent 2010;103:267-274.

16. Ashkanani HM, Raigrodski AJ, Flinn BD, Heindl H, Mancl LA. Flexural and shear strengths of $\mathrm{ZrO}_{2}$ and a high-noble alloy bonded to their corresponding porcelains. J Prosthet Dent. 2008;100(4):274-284.
17. Choi BK, Han JS, Yang JH, Lee JB, Kim SH. Shear bond strength of veneering porcelain to zirconia and metal cores. J Adv Prosthodont. 2009;1(3):129-135.

18. International Organization for Standardization. ISO 9693:1999. Metal-ceramic dental restorative systems. Geneva: International Organization for Standardization; 1999. Available at: http://www.iso.org/iso/store.html.

19. Quante K, Ludwig K, Kern M. Marginal and internal fit of metal-ceramic crowns fabricated with a new laser melting technology. Dent Mater 2008;24(10):1311-1315.

20. Vojdani M, Torabi K, Farjood E, Khaledi AAR. Comparison the marginal and internal fit of metal copings cast from wax patterns fabricated by CAD/CAM and conventional wax up techniques. J Dent (Shiraz) 2013;14(3):118-129.

21. Bindl A, Mormann WH. Marginal and internal fit of allceramic CAD/CAM crown-copings on chamfer preparations. J Oral Rehabil 2005;32(6):441-447. 